Higher Education 14 (1985) 593-616

Elsevier Science Publishers B.V., Amsterdam - Printed in the Netherlands

\title{
NEGATIVE INCENTIVE STEERING IN A POLICY NETWORK*
}

\author{
FRANS A. VAN VUGHT
}

Centre for Higher Education Policy Studies, Twente University of Technology, P.O. Box 217, 7500 AE Enschede, The Netherlands

\begin{abstract}
In this article the process of developing a policy for the recent comprehensive retrenchment operation in the Dutch university system is analysed from a theoretical point of view on decisionmaking. The article especially addresses the question whether some empirical evidence can be found for the rationalist view of collective decision-making, which states that a process of social communication should eventually lead to a unanimous and rational consensus concerning the selection of the optimal policy.

The actual analysis concerns the way a retrenchment policy has been developed in a process of social communication between the most important actors: the Minister of Education and Science and the thirteen Dutch universities. It is assumed that the various communicative linkages between these actors can be interpreted as a policy network in which both governmental and non-governmental actors operate.

The article concludes that in the Dutch university policy-network a complicated balance of interdependencies exists and that several sub-networks can be distinguished. It is also concluded that the Minister, while recognizing the interdependencies in the network, was able to use a special kind of (negative) incentive, inducing the universities to act as he wished.

This negative incentive steering, however, also persuaded the universities to go to the utmost in their consultation efforts, thus trying to reach the rationalist ideal of collective decision-making. The final conclusion therefore is that the rationalist view of collective decision-making does not appear to be unrealistic. The article ends with a warning against a common mistake made regarding the normative appearance of the rationalist perspective.
\end{abstract}

\section{Introduction}

In the literature on decision-making the rationalist perspective has an impressive history. Its roots can be traced to the empiricist philosophers of the

\footnotetext{
* The case of the policy development process concerning the retrenchment operation in the Dutch university system in 1982 and 1983.
} 
eighteenth century and even further back through the later Middle Ages to the Ancient Greeks, where the Olympic gods claimed to be far more "rational" than those other less civilised gods who had more affinity with primitive beliefs (Russell, 1971: 51). From the period of the Enlightenment on, the rationalist perspective has attracted philosophers and politicians who have tried to argue for a hypothetical rule of reason. As Mannheim (1968: 186) states:

The role of reason in human affairs and the idea of the free individual as the seat of reason are the most important themes inherited by twentieth century social scientists from the philosophers of the enlightenment.

In its simplest version the rationalist perspective is rarely doubted. The thesis that a man acts to maximize his values under the constraints he faces has hardly ever been challenged.

Recently, however, some major challenges to the rationalist perspective have emerged. It is especially the complex decisions in governmental policy processes that seem to present some basic problems for the established perspective. Moreover, according to some authors, an alternative perspective on decision-making is being developed. From the fields of cybernetics and cognitive theory new insights are being provided which, taken together, are beginning to challenge the theoretical foundations of the rationalist perspective (Steinbruner, 1974).

The rationalist perspective is met in two fundamentally different versions: the positive version and the normative version. In its positive appearance the rationalist perspective consists of a set of assumptions for explaining or predicting how actual empirical decision processes proceed. In its normative appearance, the rationalist perspective consists of a set of statements on how decisions ought to be made.

In this article I will mainly choose a positive orientation towards the rationalist perspective. After presenting a brief outline of the general features of this perspective, I will explore the level of realism of the central assumptions of the rationalist view on collective decision-making and policy development. These central assumptions concern the selection of a policy in a "community of discourse".

To be able to explore the level of realism of these assumptions, I make use of the concept "policy-network". I will try to analyse a process of collective decision-making and policy development in such a network. For this purpose a case-study is presented. This study covers the policy development process during the retrenchment operation which occurred in the Dutch university system in 1982 and 1983.

After the analysis of this case-study, I formulate some conclusions about the process of policy development in the Dutch university policy network. Finally, I 
will return to the rationalist perspective, formulating a conclusion about the level of realism of its positive appearance and a warning against a common mistake regarding its normative appearance.

\section{The Rationalist Perspective}

The most general postulate of the rationalist perspective holds that an individual decision-maker will try to maximize his values given the constraints of the situation. A rational decision-maker defines his values, analyses his information and selects that alternative from his set of options which provides him with the maximum value.

Behind these general postulates of the rationalist perspective, a number of more specific assumptions can be found which have often been the object of heated debates. Let us explore some of the more fundamental discussions concerning the rationalist perspective. The normative appearance of this perspective provides a good starting-point for such an exploration.

What are the philosophical reasons for accepting the rationalist perspective as a normative guideline? To answer this question we address ourselves to Karl Popper, who clearly indicates that a choice for the rationalist perspective is a moral choice:

The rationalist attitude is characterized by the importance it attaches to argument and experience. But neither logical argument nor experience can establish the rationalist attitude; for only those who are ready to consider argument or experience, and who have therefore adopted this attitude already, will be impressed by them (Popper, 1966: 230).

Popper (1966: 280) also argues that the rationalist perspective is related to a secular view of man as maker of himself: "Instead of posing as prophets we must become the makers of our fate."

A choice for the normative version of the rationalist perspective thus is a moral choice for a Promethean view of man. The normative version of the rationalist perspective incorporates a view of man as gaining mastery over himself by power of his faculty of reason.

But there is more to this normative rationalist attitude. In the rationalist vision a decision may only be called rational if it is the result of an evaluation of all consequences of all alternatives. If we want to take a rational decision we thus need a complete image of all the possible consequences of all the available alternatives. Besides that, we should be able to allocate weights to all these consequences and alternatives, for only then are we able to select our "optimal" solution. For reasons of briefness let us follow Camhis' stylistic presentation of the requirements of the rationalist perspective (Camhis, 1979: 30): 
(1) A general set of values expressed as goals and objectives.

(2) Generation and examination of all alternatives open for achieving the goals.

(3) The prediction of all consequences that would follow from the adoption of each alternative.

(4) The comparison of the consequences in relation to the agreed set of goals and objectives.

(5) The selection of the alternative whose consequences correspond to a greater degree with the goals and objectives.

Many authors have argued that trying to come to rational decisions in this way is unrealistic. A well-known argument is the one by Braybrooke and Lindblom (1970). They attack the rationalist perspective on some of the basic requirements mentioned above. They argue that formulating a coherent set of values is impossible, due to their fluidity and due to the fact that conflicts among values will always exist. Regarding the analysis of all alternatives and all consequences, they point at the inadequacies of theories and information gathering. Braybrooke and Lindblom's conclusion is that the rationalist perspective is fruitless and unhelpful as an ideal because it does not "take into account the manifold difficulties ... that beset social analysts and evaluators in the real world" (Braybrooke and Lindblom, 1970: 16).

This is a positive argument against the rationalist perspective. Braybrooke and Lindblom describe a number of practices which differ widely from the normative rationalist ideal and which prove to be fruitful to their users when coping with the difficulties of decision-making. This makes their work very important, especially since several studies have endorsed their conclusions about the actual practices of decision-making (Wildavsky, 1974; Bailey and O'Connor, 1975; Schulman, 1975).

But the question is whether the finding that many actual decision processes do not resemble the rationalist ideal implies that the ideal therefore is not worthwhile. On this question opinions diverge. On the one hand there is a group of authors who seem to be convinced that the rationalist attitude should be done away with as soon as possible. Braybrooke and Lindblom (1970: 22, 23) are convinced that the rationalist attitude should no longer be considered as a normative guideline:

In what sense do these systems represent worthy aspirations? Analysts typically do not hold the proposed methods to be worthy aspirations on grounds that within a few generations it will be possible to construct a rational-deductive system or a welfare function. Rather, they aspire to them in the belief that to be closer to achieving their construction is better than being farther away. They assume, first, that part of such a system is better than no part of the same system and, second, that part of such a system is better than any alternative realizable system.

But, as we shall see, much of the attraction of these systems lies in their promise of comprehensiveness; and one can doubt the usefulness of quite incomplete rational-deduc- 
tive systems or welfare functions. Even more important is the principal thesis of this book that social analysts have in fact hit upon a mutually reinforcing and defensible set of evaluative practices that, if clearly understood, would raise great doubts in their own mind as to whether the received ideals are worth aspiring to even as ideals.

On the other hand, there is a group of authors who, although accepting the criticism on the rationalist perspective, are not willing to abandon the perspective as a normative ideal. Etzioni, for example, has argued that the necessary calculations assumed in the rationalist perspective cannot be carried out. Firstly, the decision-makers do not have all the relevant information they would need to examine all consequences of all alternatives. Secondly, they do not know how much of the information they have is really necessary and/or valid (Etzioni, 1968: 265).

But Etzioni does not seem to completely reject the rationalist perspective as a normative ideal. He presents his model of "mixed scanning" as an adaptation of the rationalist perspective (Etzioni, 1968,: 282) and seems to hold on to what he feels is a less unrealistic rationalist ideal. In his own way Etzioni seems to express the same view as Simon, who calls his "satisfizing man" a modest cousin of the "maximizing man", this modesty being the result of the fact that the satisfizing man does not select the best alternative among all those available to him, but looks for a course of action that is satisfactory or "good enough" (Simon, 1976: xxix).

Both Etzioni and Simon, and with them many other advocates of the rationalist perspective, frankly admit that the ultimate requirements of this perspective may be unrealistic. But they nevertheless want to hold on to the ideal, simply because it serves the process of justification of decisions (Solesbury, 1974: 141).

\section{The Rationalist View of Collective Decision-making and Policy Development}

A special problem with the rationalist perspective comes to the foreground when it is applied to the process of collective decision-making and policy development. When more than one actor is involved in a process of decisionmaking, the rationalist requirement of formulating and integrating values must be shared by all those participating in the process. Also, the rationalist analysis of all consequences of all alternatives should take place in such a way that every participating actor can agree. However, there is more than one way of perceiving reality and there are many values an individual actor can pursue. In a process of policy development the various subjective preferences and images therefore can differ widely (Ackoff and Emery, 1972).

The rationalist view of collective decision-making and policy development 
addresses this question of coordinating individual preferences and images in a special way. It states that a process of social communication should eventually lead to a unanimous and rational consensus concerning the selection of the optimal policy. This view can be traced back to the basic rationalist attitude, described by Popper (1966: 225) as the attitude of saying: "I may be wrong and you may be right, and by an effort we may get nearer to the truth."

The rationalist view of collective decision-making involves the possibility of criticising both factual and value propositions. In an open process of social communication, the consequences of every proposition should be completely discussed so that finally an agreement can be reached on the policy which should be adopted. As such, the rationalist process of adopting a policy in a process of social communication may be compared to the process of adopting a proposition in scientific research.

... both propositions, which state facts, and proposals, which propose policies, including principles or standards of policy, are open to rational discussion. Moreover, a decision one, say, concerning the adoption of a principle of conduct - reached after the discussion of a proposal ... may be in many respects very similar to a decision to adopt, as the best available hypothesis, a proposition which states a fact (Popper, 1966: vol. II, 384, 385).

Following Popper, Collingridge (1982) came to the conclusion that a rationalist approach to collective decision-making should be based on the fundamental conception that preference judgements, although impossible to justify, may be assessed by exposure to criticism in a rational discussion.

\footnotetext{
Making a social choice is not finding some reasonable compromise between the fixed values of the individuals concerned. On the contrary, disagreement is resolved by some of the people involved in the decision changing their views about what their interests are, realizing that their original opinions about what the group should choose were mistaken. Each person tries to convince those in opposition to him that the option which really serves their individual interests is the one which he thinks serves his own. Thus debate and not compromise is the key to the making of social decisions (Collingridge, 1982; ix).
}

It may be concluded that in the rationalist view of collective decision-making and policy development two conditions should be met. The first is that there should be a "community of discourse" embracing all those concerned. The second is that this discourse should lead to an agreement concerning the selection of the optimal policy (Faludi, forthcoming, ch. 8).

Again, opinions diverge as to whether this rationalist view of collective decision-making and policy development is an ideal that should be strived after or done away with. On the one hand there are, as Elster indicates, many authors who differ strongly in many respects, but who agree on the need for "purging the private, selfish or idiosyncratic preferences in open and public debate". They all agree on the central assumptions of the rationalist view of politics and policymaking: 
The goal of politics should be unanimous and rational consensus, not an optimal compromise between irreducibly opposed interests. The forum is not to be contaminated by the principles that regulate the market, nor should communication be confused with bargaining. From these contrasts it is easy to identify the writers I have in mind. They include Rousseau and Hegel, Hannah Arendt and Jürgen Habermas... (Elster, 1983: 35).

On the other hand are the authors who think that the rationalist view of collective decision-making and policy development is unrealistic and useless. Steinbruner, for instance, concludes that there are formidable logical barriers to extending the rationalist analysis of individual decision-making to the collective level (Steinbruner, 1974: 36). In criticising Habermas' ideal of discourse, Weinrich explains that the formulation of the ideal itself can stimulate the participating actors in a decision-making process to develop special strategies which make the ideal both unrealistic and unattainable and which eventually lead to the "dictatorship of the rear" (Weinrich, 1971).

In the rest of this article I will concentrate on the question whether some empirical evidence can be found for the rationalist view of collective decisionmaking and policy development. I will introduce the concept "policy-network" as an institutional approximation of the rationalist view of the "community of discourse". The analysis of an actual process of collective decision-making and policy development in such a policy-network will hopefully provide us with some indications concerning the realism of the central assumptions of this rationalist view.

\section{Policy-networks}

In the 1960s the emphasis in organizational theory shifted from controlling internal activities to managing external constraints. Attention was paid to the various aspects of resource control and to the organization-environment interface, where the management of uncertainty was a prominent theme. Later on, the collaborative agreements between organizations and the various coordination strategies became important issues and a conceptual consensus was developed on the nature of "networks", which were described as a composition of organizations connected by a certain type of relationship (Aldrich, 1979; Aldrich and Whetten, 1981).

Whetten (1982: 107-108) notes that in organization theory three principal dimensions have so far been used in characterizing networks:

1. Centrality. This is the number and the length of all linkages between one organization and all other organizations in the network.

2. Complexity. The extent of functional dissimilarity of goals, services, products, or target populations a mong organizations in the network. This is sometimes referred to as domain similarity or functional differentiation. 
3. Density. The extent to which members of a population or network are directly linked to one another. This is also referred to as cohesion or connectedness.

In several other disciplines a related conceptual development took place. In social systems theory, an "actor-oriented systems analysis" appeared in which "social action systems" are presented as systems that shape and transform the conditions for social activity.

Social action systems consist of patterned social action and interaction, which are shaped and influenced by - at the same time that they produce, reproduce, and transform material, social structural, and cultural constraints (Baumgartner et al., 1978: 40).

In policy analysis some attempts were made to develop a conceptual framework which is very much akin to the organizational network approach. Critiquing traditional policy analysis as "mono-centric", Gregg, for instance, pleads for an approach in which a network-like perspective can be found. In this perspective:

decisions are regulated by the exercise of concurrent powers among semi-autonomous officials rather than by the exercise of hierarchical powers inferred by a single encompassing government or department (Gregg, 1976: 64).

In urban and regional planning, both the study of the interaction of networks in an urban setting (Warren et al., 1974) and the analysis of the vertical interactions between semi-autonomous actors and different levels of government (Friend et al., 1974) should be mentioned.

Recently, in public administration the network concept has also come to the fore. Milward and Francisco (1983) trace the emergence of this concept back to the concept of "subsystem politics", originally defined as:

...the politics of function, involving the interrelations of bureaux and other administrative operating agencies, the counterpart congressional committee structure, and the interest organizations, trade press, and lobbyists concerned with a particular area or programme specialization (Redford, 1969: 83).

Subsystem politics is also known under names as "the triple alliance" and "the iron triangle", indicating that in this form of policy-making executive organizations, legislative committees and interest groups are strongly interrelated. In many western nations subsystem politics - Lowi speaks of "interest group liberalism" - has to a considerable extent replaced traditional party politics in the process of policy development, leading to an increasing professionalisation of policy-making and to the rise of single-issue interest groups. A major development following this professionalisation and the rise of interest groups is the emergence of "policy-networks" (Heclo, 1978; King, 1978). 
The policy-network consists of all those interested in the benefits that may flow from a policy domain, but not all of its members are capable of affecting the distribution of the benefits.

The policy-network constitutes a form of social network in the sense used by social anthropologists in that it is shaped by patterns of relations in which each individual has developed a communication linkage with at least one other member of the network, but is not necessarily fully connected to every other member.

In the policy-network the unit of analysis consists of individuals, parts of organizations and coalitions of organizations.

The character of the network is formed in part by the extent of "indirect administration" in which the ... government assumes relatively few administrative functions (Milward and Francisco, 1983: 283-285).

Trying to relate to the conceptual innovations in the various disciplines mentioned, I will speak of a policy-network as a system characterized by the following components:

- a set of actors (individuals, parts of organizations, organizations, coalitions of organizations);

- a set of activities, problems or issues with respect to which the actors have certain interests and goals;

- a set of norms, rules and assumptions, defining the situations in which the actors interact and communicate, and defining the forms of interaction and communication the actors have at their disposal;

- the distribution of the action, interaction and communication possibilities among different actors or categories of actors;

- the set of likely outcomes (costs and benefits) of the actions, interactions and communications for the different actors or categories of actors.

Besides these components some specific characteristics of a policy-network can be mentioned.

1. A policy-network consists of actors who try to influence (to use Easton's words) the authoritative allocation of values. These values may be rewards (financial resources, services, status) or deprivation (punishment, taxation, budget cuts, status denigration).

2. The actors of a policy-network can in various ways be interrelated. When many interrelations exist the network may be called "dense". The nature of the interrelations may differ from cooperation towards competition and conflict.

3. Policy-networks may have either a more or less permanent, or a temporary character. Aldrich and Whetton (1981) distinguish "networks" and "action sets", a network being more permanent than an action set. I will speak of permanent and temporary policy-networks. 
4. A policy-network consists of governmental as well as non-governmental actors. In general the governmental actors leave the administrative functions to the other actors in the network. "Policy-network comprise a set of interorganizational relations that receives a mandate from the state to act in its name in a limited area and to allocate state funds" (Milward and Francisco, 1983: 285).

5. The linkages between the actors of a network can be horizontal as well as vertical. However, in a policy-network the emphasis will be on the horizontal linkages, making traditional bureaucratic or corporate coordination by means of centralised authority of little value.

6. The configuration of power in a policy-network may vary from oligarchy to anarchy. Often a dominant coalition of actors will be found, which may be characterized as a polycentric power configuration. Polycentricity refers to a pattern where the power is distributed over many interdependent but relatively autonomous actors.

7. A special type of relation between the actors of a policy-network has to do with resources. Resources may be conceived as the elements which an actor requires to meet his conditions for survival or performance (financial resources, authority) (Benson, 1982). The resource dependencies between the actors of a policy-network to a large extent define the power configuration of that network.

If we recapitulate some of the central characteristics of the concept of "policynetwork" we may justifiably come to the conclusion that a policy-network can be seen as an operational elaboration and an institutional approximation of the rationalist ideal of collective decision-making and policy development by means of the "community of discourse". When we realize that interaction and communication are of extreme importance in a policy-network and, moreover, when we pay attention to the prevalence in a policy-network of horizontal linkages and polycentric power configurations, we may agree that a process of policy development in a policy-network should be able to provide us with some interesting empirical notions for a positive orientation towards the collective rationalist perspective.

In the literature on policy analysis and especially on policy instruments, we find an interesting argument for this point of view. Several authors (Mitnick, 1980; Hood, 1983; Mayntz, 1983) have argued that the selection of a policy instrument by a governmental organization should be contingent on the context it will be used in. They suggest that a governmental organization, when confronted with a group of actors in a policy-network, should rely more on indirect types of instruments (persuasion, incentives) than on direct actions. 
The power of these [actors of a policy-network] rests on the control they have over their members... The government in particular can avail itself of this control by getting an organization to support a policy decision affecting its members... The indirect mode of control established in this way lies at the core of what has recently been widely discussed as "neo-corporatism" (Mayntz, 1983: 140).

The preference for indirect types of instruments in policy-networks may be interpreted as another argument for choosing a policy development process in a policy-network as an approximation of the collective rationalist ideal. Paraphrasing Mayntz, we could say that the very use of these instruments in a policynetwork is predicated upon the assumption of the existence of a situation where the various actors tend to have the best possibilities for a genuine discourse, leading to the selection of the optimal policy (Mayntz, 1983: 140).

\section{The Dutch University System}

The Dutch university system consists of thirteen institutions, with a total enrollment of 140,000 to 150,000 students. Each institution is organizationally autonomous, all institutions are equal in the sense that they all offer students the opportunity to acquire a master's degree, and that all of them are entitled to let students write a thesis and acquire $\mathrm{PhD}$. There are six general state universities, organized as public authorities. Furthermore there are three technical state universities and one agricultural state university. Finally, three general universities are private institutions.

Together the universities offer a broad range of curricula. The larger universities contain ten to fifteen different faculties, which in turn encompass 40 to 50 different subfaculties or departments.

The universities also have an important research task, which is of great social and scientific value. In general the initiative to undertake research comes from the researchers themselves. The financing of research takes place through various funding procedures. Of the nearly 37,000 people employed by the universities, approximately $50 \%$ of them are scientific personnel.

The national government provides almost $100 \%$ of the financial resources of all institutions. Together the universities receive about $f 4,000,000,000$ $(\$ 1,300,000,000)$ per year from the national government. Compared to this, all other sources of university income are negligible. About $75 \%$ of the financial resources provided by government is used for personnel costs.

The relationships between government and the universities are direct and regulated by several laws. The universities are completely autonomous in managing their internal affairs, especially regarding the activities of teaching and research. The government can influence the system using funding methods and special regulations concerning the overall structures of teaching and research. 
Until the middle of the 1970s, the funding of the universities was on a year-to-year basis. The funding of both teaching and research activities was based on the student enrollment figures. However, as Fig. 1 indicates, student enrollment figures began to fall and since more drastic enrollment declines are forecasted, new ways of funding are now being developed.

The enrollment declines, together with many other economic and social developments, have forced the government and the universities to develop new policies concerning the overall operation of the university system. The period of growth seems to be over. The university system will have to come to terms with the "three r's of the 1980s: reduction, reallocation, and retrenchment" (Peterson, 1981).

On 16 November 1981 the Dutch Minister of Education and Science wrote a letter to parliament indicating that the way by which the budget cuts in the university system until then had been realised (by means of pro rata) was no longer acceptable. A new way of cutting down the expenses in the university system had to be found. This date marks the beginning of an important and far reaching retrenchment operation in the Dutch university system. I will describe the policy development process concerning this operation in detail below. First,

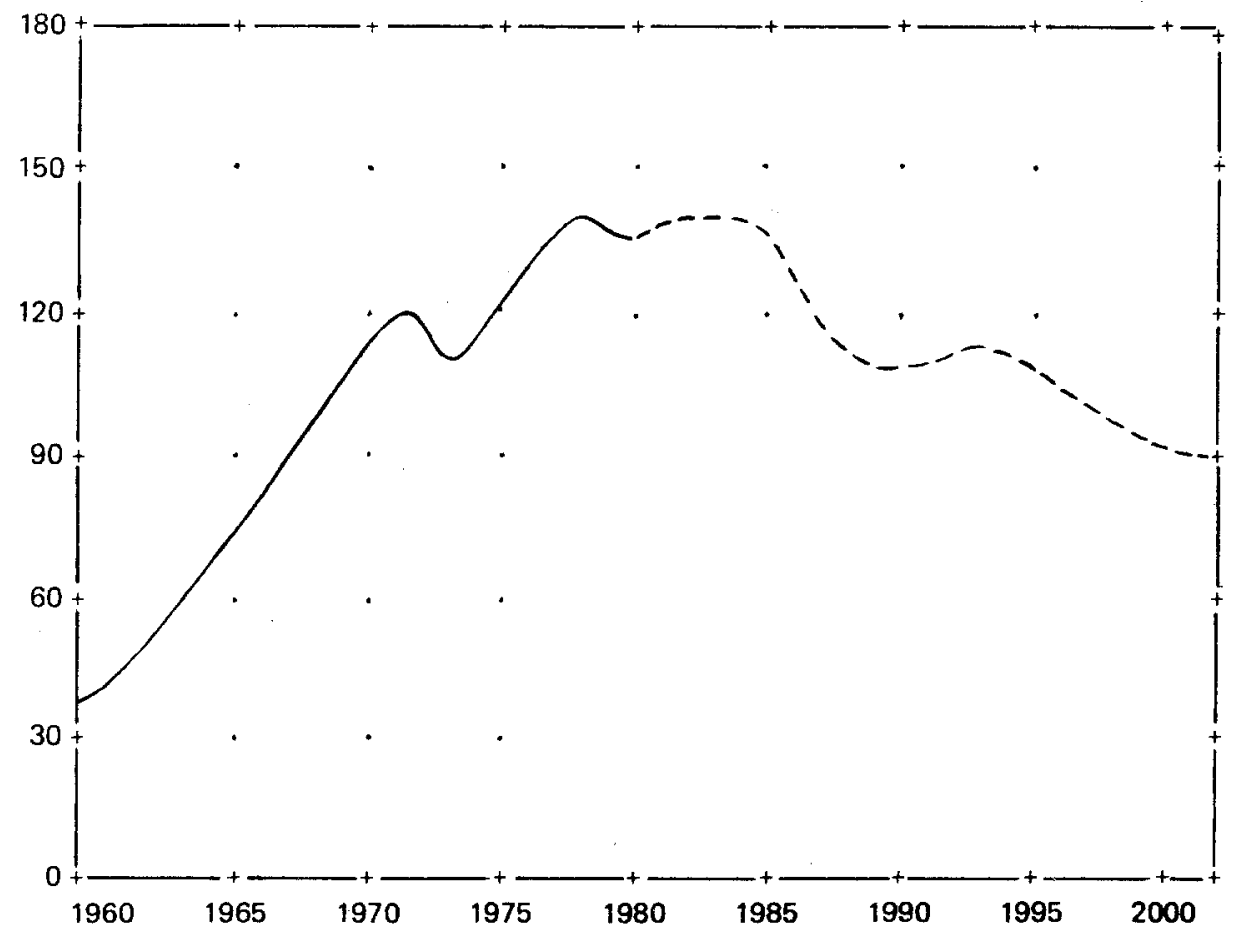

Fig. 1. Student enrollment in the Dutch university system. 
however, I will try to indicate that the steering of this process was in the hands of many actors, who together formed a policy-network.

\section{The Dutch University Policy-Network}

Who then are the actors involved in the process of policy development that occurred during the retrenchment operation in the Dutch university system? Of course, the most important actors are the Minister of Education and Science on the one hand, and the thirteen universities on the other. But to get a more complete picture, we have to look closer. Let us try to make an inventory of all the actors involved and of their various interrelations.

The Minister of Education and Science has the formal political responsibility for the functioning of the university system. He has the authority to allocate tasks and resources to the universities by means of the funding instrument. This authority is based on the "law concerning scientific education" (WWO), enacted in 1960. A decision concerning an allocation or reallocation of tasks is taken by the minister, after having consulted with the universities and after having heard a special advisory council known as the Academic Council.

The Academic Council is an organization instituted by law in which all the universities are represented. Its objective is to maintain the horizontal coordination between the universities in order to be able to advise the Minister of Education and Science. In practice, the universities often use the Council to try to persuade the minister to satisfy their wishes.

To perform his tasks, the Minister of Education and Science has at his disposal the Department of Education and Science. Within this department it is the "Directorate-General for Higher Education and Scientific Research" (DGHW), which to a large extent is oriented towards the university system. With regard to the retrenchment operation, which will be described below, within this directorate-general a special taskforce was created.

The thirteen universities are all governed by their own boards and councils. These two bodies are responsible for the university policies concerning the teaching and research activities and concerning the personnel and material resources. The university board acts as the daily committee; the university council decides on the general policy lines. Within each university, the various faculties and subfaculties organize, manage and realize the programs for teaching and research.

Between the universities several forms of consultation exist. Most of these consultation activities are directed towards the coordination of individual policies, to be able to face the minister jointly. The most important consultation bodies of the universities are: 
- the Academic Council

- the college of the vice-presidents for academic affairs

- the general assembly of the presidents

- the consultation of the portfolio-holders of finance

- the consultation of the portfolio-holders of planning

- the consultation of the portfolio-holders of research

- the consultation of the portfolio-holders of personnel

- the consultation of the portfolio-holders of building and housing

Only the consultation of the portfolio-holders of planning has a certain formal status. This consultation body, called the "Permanent Planning Committee" (PPC), is an official committee of the Academic Council.

Of all the consultation bodies mentioned, the meetings of the portfolioholders of planning and of personnel appeared to be the most important for the recent retrenchment operation. This can be explained by the fact that these portfolio-holders play an important role in the consultation processes in which the minister also participates.

The consultation processes between the Minister of Education and Science (or his representatives) on the one hand and the universities on the other hand are institutionalised in several bodies. For our purposes, the consultation bodies for planning and personnel are the most important.

Let us first make an inventory of the consultation bodies on the subject of planning. The first consultation body that should be mentioned in this respect is the "Multi-lateral Consultation Organ" (MLO). The MLO is not really an official organ with appointed members. It is rather a general forum where the minister and the universities negotiate - among other things - the national budget for scientific education and research.

A second consultation body is the "Planning Consultation Organ" (POO). This is an official body which is composed of thirteen representatives of the universities, twelve representatives of the schools for higher vocational education (an important sector of the system of higher education in the Netherlands, not dealt with in this article) and several advisors and observers, among whom are representatives of the minister. In the POO procedural questions are mainly discussed, especially those concerning the methods and criteria for allocating funds.

The meetings of the POO are prepared by the "Advice Group for Planning" (AGP). This group acts as the agenda committee for the POO. The members of the AGP are appointed by the minister after nomination by the POO. Usually the members of the PPC, the consultation body of the portfolio-holders of planning (see above), are also AGP members. The AGP often establishes taskforces to study special policy problems.

For matters of personnel, two important consultation bodies exist. First 
there is the "Consultation Organ for Personnel Affairs in Scientific Education" (OPWO). In this body the portfolio-holders of personnel of the universities discuss personnel matters with the appropriate officials of the Department of Education and Science.

Also, the "Central Consultation Organ for Personnel Affairs in Scientific Education" (COPWO) should be mentioned. This body operates as an offical consultation organ with the trade unions. In the COPWO four different union federations on government-personnel affairs are represented. The Department of Education and Science also has some official representatives in this organ.

Looking at the various actors and their interrelations mentioned, we may speak of a policy-network. In this network both governmental and non-governmental actors are involved. The main actors are the Minister of Education and Science and his department, and the thirteen universities. The Department of Education and Science and the universities are linked by a complicated pattern of relations. Neither the minister and his representatives, nor the universities are able to steer the policy processes completely according to their own will. The minister may try to initiate certain policy processes; for their actual implementation he cannot do without the cooperation of the universities, which have the right to veto certain decisions of the minister.

The relations between the actors in the network are elaborated in the horizontal linkages in the various consultation bodies. In these bodies the actors have to come to an agreement concerning the policies that should be adopted. The communicative linkages between the actors are supposed to lead to the policy decisions that every actor can agree on. Direct communication and interaction play an important role in this whole setting.

\section{The Policy Development Process during the Retrenchment Operation in the Dutch University System in 1982 and 1983[1]}

On 16 November 1981, the Minister of Education and Science wrote a letter to parliament. In this letter the minister declared that a severe cutback in the funds for the university system was inevitable. However, the national research efforts needed to be maintained. The retrenchment would take place by reallocating tasks between the universities. The minister indicated that the budget cuts would rise from 20 million guilders in 1983, to 60 million guilders in 1986. If more cutbacks were necessary, they would be realized by a more comprehensive reallocation of tasks.

The minister raised this matter in the MLO and in the POO. Already at the 11 December meeting of the PPC of the joint universities, a choice was offered: the universities could either try to defend the existing situation, claiming that budget cuts were impossible, or they could try to anticipate the new develop- 
ments and themselves start to discuss the possibilities of a reallocation of tasks. The PPC did not come to a definite conclusion. The governing boards of the thirteen universities were asked to give their opinions. On 2 March 1982, the AGP - the agenda committee of the POO - established a taskforce to explore the procedures that could be followed for a reallocation of tasks. The taskforce began to work on a report. In the meetings of the COPWO and the OPWO the employment aspects of a reallocation of tasks were discussed. In the COPWO a plea was made to develop a social policy related to the retrenchment operation.

On 7 July, the report of the taskforce of the AGP was published. Three models concerning the administrative elaboration of the reallocation of tasks were presented. In the first model the minister took a number of successive decisions on the reallocation of tasks; in the second he developed a reallocation plan and discussed this with the Academic Council; in the third model the universities jointly established a "reallocation organ" which would give advice on a plan for the reallocation of tasks.

In the August meeting of the PPC, an agreement was reached concerning the third model. The universities would establish a "reallocation organ" which would give advice on a reallocation plan. In the meeting of the MLO, the minister declared that he would take note of the preference of the universities concerning the three models. He also declared, however, that he would develop his own reallocation plan if the universities were not able to provide him with their reallocation advice before 1 March 1983. Moreover, he indicated that severe budget cuts could be expected if the reallocation advice from the universities did not satisfactorily deal with the problem.

On 1 September, the minister published his official document, called "Task Reallocation and Concentration in Scientific Education". This document became known as the TVC Report and from then on the whole operation was called the TVC operation. The report pointed out that the budget cuts would have to be more severe than expected. Instead of 20 million guilders in 1984 and 60 million guilders in 1986, the cuts would rise from 66 million guilders in 1984 up to approximately 258 million guilders in 1987 . The suggestion was made that $35 \%$ to $40 \%$ of the total cuts would be in the costs of the medical faculties and the academic hospitals.

In a letter the minister asked the universities to inform him as to their preferences concerning the administrative elaboration of the whole operation. After a discussion in the PPC, the universities responded in a letter dated 27 September and the reallocation organ, called the TVC committee, was established. The members of the TVC committee were nearly all portfolio-holders of planning in their own university, and thus also members of the PPC.

The TVC committee started its activities on 8 October. Exactly one year after the minister wrote his first letter to parliament, 16 November 1982, the TVC committee published its first report. In this report various types of reallocation 
were distinguished and a general procedure for the whole operation was proposed. The universities agreed with this procedure and the committee continued its work which included discussing some matters with the minister. The minister wrote a letter to the committee, explaining that he would test the final proposals of the committee against some general criteria.

In the meetings of the organs on personnel affairs (OPWO and COPWO) some problems arose concerning the social policy which would have to be developed in relation to the TVC operation. On 7 March 1983 the minister wrote a long letter to the COPWO, indicating that concrete agreements would have to be made.

In the meantime, the minister received approval for this decisions in parliament. In the meeting of the Parliamentary Committee on Education and Science of 24 February 1983, nearly all parties supported the general policy of the minister.

The final report of the TVC committee was published on 11 March 1983. After many consultations with the boards of each university, the committee appeared to have succeeded in drawing up advice which received the support of all the universities. The only part that failed was the set of proposals for the medical faculties and the academic hospitals. Having finished its task, the TVC committee ceased to exist.

After a few weeks the minister formulated his first reactions. He praised the committee for the solid way in which it had performed its tasks. But he also indicated that the proposed concentration of activities was not enough, and he developed some alternative proposals. The universities were shocked. In a letter of 12 April from the PPC to the minister the universities expressed their alarm. They also indicated that a greater concentration of activities, as proposed in the reaction of the minister to the report of the TVC committee, was unacceptable due to the great personnel problems that would be involved. On 14 April an informal meeting between the minister and the universities took place and the problems were resolved.

In the meantime each university formulated an official reaction to the advice of the TVC committee and sent it to the minister. The officials of the Department of Education and Science started working on the "concept of policy intentions" that was to be discussed with each university separately. A policv intention is a final agreement between the minister and a university on all possible measures concerning the functioning of that university, except for a measure to alter the curriculum.

For the medical faculties and the academic hospitals there were still no agreed proposals. The minister made a first general proposal and in an informal meeting with the minister the universities (including the academic hospitals) agreed to respond to the minister's suggestion before 31 May. On 17 May, the minister published his concept of policy intentions, which still contained several 
modifications of the proposals originally made by the TVC committee. The officials of the Department of Education and Science now started a great number of bilateral and multilateral consultations with the universities. An agreement had to be reached with each university concerning the policy intentions. These consultations went on until 15 June. Little progress was made concerning the medical faculties and the academic hospitals. There was still no plan when a formal meeting with the minister took place on 16 June. The boards of the universities declared that a completed plan would be provided before 25 August. In the beginning of July the minister sent the concept of policy intentions statement to the universities, asking them to let him know before 20 August if they would give their agreement. On 13 July, the minister also sent his policy intentions to parliament. These intentions contained the concept proposals discussed with the universities, as well as a number of proposals to end the funding of certain activities. In the summer some problems arose concerning the personnel aspects of the whole operation. In a COPWO meeting the union federations broke off the consultation process. During a meeting of the Parliamentary Committee of Education and Science on 12 August, the minister was advised to reopen the negotiations with the union federations. This aspect apart, parliament remained supportive of the proposals. However, by the end of the summer of 1983 there was still no plan for retrenchment in the medical faculties and the academic hospitals and consultations continued.

Mean while the various university councils discussed the concept of policy intentions and finally eleven of the thirteen universities decided to conclude an agreement.

The consultations with the union federations started again in September and on 11 November an agreement was reached and a social policy established. On 16 November, parliament discussed the policy intentions. In general parliament agreed with the various intentions. There was, however, a vote concerning the proposed closing down of a dental surgery curriculum. The minister was asked not to go on with this proposal but he ignored the vote.

On 15 December, the minister sent his final tasks-reallocation plan to parliament. With this final document the process of policy development concerning the retrenchment operation in the Dutch university system ended.

\section{Conclusions}

The policy development process described above makes clear that in the Dutch university policy-network a complicated balance of interdependencies exists. The description of the policy development process also indicates that in this process several subnetworks with different characteristics were involved (Grondsma, 1983). 
First there is the subnetwork in which both the minister and the universities participate. In this subnetwork the interdependency between the minister and the universities is very clear. The minister has the official authority to allocate funds and tasks. The universities have the competence to organize (and start and end) teaching and research activities. The minister mainly acts as the provider of state funds. The universities perform the administrative functions for realizing the teaching and research activities. The minister depends on the universities regarding the operational activities in the university system. The universities depend on the minister regarding the funding of those activities.

Both actors in this subnetwork depend on one another to reach their common goal: the production of high-grade scientific education and research. This common goal binds them together. But each actor also has his own interest, which conflicts with the other actor's interest. The minister is committed to perform the budget cuts in the university system, because of the decisions made in the cabinet council and in parliament. The universities will always try to prevent the budget cuts because of their inclination to maximise their budgets.

In this subnetwork two important consultation bodies exist where the two actors try to reach an agreement with one another: the MLO and the POO. Both these organs are poorly institutionalised. The MLO only functions as a forum for consultation, where no decisions can be taken. In the POO decisions can be taken, but the minister is not obliged to keep his word.

The rules of the game are rather vague and, looking at the history of the policy development process described, it seems that the minister has been able to take advantage of this situation. After the universities had declared that they wanted to establish a reallocation organ (the "TVC committee") to advise on a joint reallocation plan, the minister threatened that he would make more severe cuts if this advice were insufficient. Besides that he did not just accept the final advice of the TVC committee; he formulated several modification proposals and succeeded in getting the universities to accept these proposals.

A second subnetwork which appeared to be important in the policy development process is the personnel subnetwork. In this network the main actors were the minister and the union federations. They discussed the social policies that should be related to the retrenchment decisions.

In this setting no direct interdependencies exist. Both actors only communicate with one another because they are obliged to by an offical order in council. The consultation activities therefore mainly had the character of a formal negotiation process, in which finally an agreement could be reached.

A last, and very special, subnetwork is the reallocation organ established by the joint universities: the TVC committee. In this committee the thirteen universities are the actors. The committee is a temporary policy-network. After having produced its final report, the committee ceased to exist.

In principle the interests of the actors in this network conflict: when one 
university could be forced to accept a greater cutback, another university could have the advantage of a smaller cutback. In the process it appeared, however, that the universities were able to emphasize their common interests. The advice of members of the committee could be supported by each university.

It is quite possible that the fact that the minister was seen as the "common enemy" triggered the universities' solidarity. The minister had threatened severe cutbacks if the universities would not themselves produce a concept plan. The universities decided not to let the minister interfere with the reallocation of tasks. Had they not decided in this way, the minister could have acted as he pleased, and he could have accused the universities of not being able to draw up a plan for their own future.

In all three subnetworks intensive forms of interaction and communication are found. As such it may be concluded that the policy development process during the retrenchment operation in the Dutch university system took shape through several processes of interaction and communication. As far as the relationships between the actors in the various subnetworks are concerned, it should be noted that several interdependencies exist and that the horizontal linkages seem to prevail over the vertical linkages.

There is one special relationship which appeared to be of conclusive importance for the whole process: the relationship between the minister and the universities. From the analysis of the policy development process, it may be concluded that the minister, while recognizing the interdependencies in the network, was able to use a special kind of incentive to induce the universities to act in a way he thought was fruitful. The minister used his financial powers to let the universities themselves design the policy proposals for the retrenchment operation. By formulating the financial constraints that should be met and by threatening more severe budget cuts in the case of failure, the minister used the strategy of "cheque-book government":

\footnotetext{
The great advantage of cheque-book government, as opposed to the other kinds of effectors available to government, is that it can be used to further purposes which government cannot completely specify - not merely to secure obedience or compliance, but to induce its subjects to positive or creative activity or to choose the best means of achieving some broadly specified goal (Hood, 1983: 52).
}

The minister used his strategy in a negative form. The minister may be said to have used a form of negative incentive steering. He threatened to punish the other actors in his policy subnetwork: if they did not behave as he wished, they might be confronted with the negative consequences of their refusal.

This negative incentive steering strategy persuaded the universities to act jointly. Because of the threat of the minister, the universities did their utmost to reach a complete consensus concerning their advice on the reallocation of tasks. The fact that one actor in one subnetwork was able to use a negative incentive 
strategy made thirteen actors in another subnetwork (the TVC committee) decide to go to the utmost in their consultation efforts.

\section{A Final Note on the Rationalist Perspective}

Where does this lead us with relation to the rationalist view on collective decision-making and policy development? Does the analysis of the policy development process in the Dutch university policy-network provide us with some empirical evidence for the rationalist view on collective decision-making and policy development?

If there is some empirical evidence in this case-study, it must be found in the activities of the temporary subnetwork of the joint universities. Both other subnetworks certainly cannot be characterised as a "community of discourse", where in an open debate an optimal policy is agreed upon. These two subnetworks rather appear to be settings for negotiation and bargaining, where every actor tries to protect and to pursue his own interests.

Whether the discussions in the subnetwork of the thirteen universities did or did not proceed according to the rationalist view, is hard to tell. A set of in-depth interviews with the members of the TVC committee could perhaps shed some light on this matter. It can be concluded, however, that a number of conditions for a "community of discourse" certainly existed. The social communication process could take place in a rather relaxed atmosphere, because the members of the TVC committee knew each other well from the PPC. The negative incentive steering strategy of the minister also induced the members of the committee to explore as many alternatives and consequences as possible and to finally design an optimal concept-plan under the constraints they were facing.

The conclusion must be that in one of the three subnetworks analysed, the rationalist view of collective decision-making and policy development does not appear to be unrealistic. A comprehensive analysis of the discussions and debates in this subnetwork is necessary to be able to formulate a more definite conclusion.

Finally, several authors have argued that the rationalist perspective is fruitless because it is an unrealistic ideal (see above). In the case-study presented here, however, some indications were found that the rationalist view of collective decision-making and policy development can be met within an empirical policy development process. The perspective does not seem to be as unrealistic as some authors are inclined to believe.

But, perhaps more importantly, the results of a positive analysis of the rationalist perspective cannot provide us with any argument concerning the question whether this perspective is worthwhile. I therefore do not formulate any conclusion regarding this question. The results of the case-study on the policy 
development process concerning the retrenchment operation in the Dutch university system should not tempt us to conclude that the rationalist perspective is, or is not, worth while as a normative guideline. The only conclusion which seems to be correct is that, as a set of positive assumptions, the rationalist perspective is not unrealistic.

As indicated above, several authors have come to the opposite conclusion. Moreover, many of them have declared that the rationalist perspective is therefore not worth while as a normative guideline. However, there is no reason at all to abandon the rationalist ideal when some, or even many, empirical decision processes appear to differ from this ideal. There also is no reason to try to adapt the ideal to the experiences in actual decision processes. As a matter of fact, such adaptations only make the normative ideal less worthwhile, because the result is a strange mixture of methodological rules and practical experiences.

When a positive analysis of the rationalist assumptions brings us to the conclusion that these assumptions are not supported by empirical evidence, we can try to explain why such empirical evidence is lacking. We can try to develop a theory concerning the lack of this evidence, that is: concerning the question why in practice decision processes do not follow the rationalist assumptions.

To use the lack of empirical evidence concerning the assumptions of the rationalist perspective to attack the perspective as a normative guideline is a mistake. An empirical analysis can never prove a normative ideal to be right or wrong. As a normative guideline the rationalist perspective cannot be falsified by empirical tests, as a hypothesis can be falsified by empirical tests. As a normative guideline the rationalist perspective is a methodological theory.

That this mistake is often made can be concluded from the amusing little quarrel between Lakatos and Popper. In his "Replies to my critics" Popper mentions a question which Lakatos once asked him: "But is your own theory of falsibility ... falsifiable?" Popper (1974: 1010) replies as follows:

Now, while this is a very natural question, it should not be asked by anybody familiar with my work. For the answer is that my theory is not empirical, but methodological or philosophical, and it need not therefore be falsifiable.

As regards the normative appearance of the rationalist perspective, we should hold on to the same view: as a normative guideline the rationalist perspective is a methodological theory; it cannot be empirically falsified.

\section{Notes}

1 This paragraph to a large extent is based on: T. Grondsma, TVC-proces en speltheorie, Delft, The Netherlands, December 1983 


\section{References}

Ackoff, R. L. and Emery, F. E. (1972). On Purposeful Systems. New York: Atherton.

Aldrich, H. E. (1979). Organizations and Environments. Englewood Cliffs: Prentice Hall.

Aldrich, H. E. and Whetten, D. A. (1981). "Organizational sets, action sets, and networks-making the most of simplicity," in: P. Nystrom and W. H. Starbuck (eds.), Handbook of Organization Design. London: Oxford University Press.

Bailey, G. G. and O'Connor, R. J. (1975). "Operationalizing incrementalism," Public Administration Review 35: 60-66.

Baumgartner, T., Burns, T. R. and DeVillé, P. (1978). "Actors, games and systems: the dialectics of social action and system structuring," in: R. F. Geyer and J. van der Zouwen (eds.), Sociocybernetics. Vol. 1. Leiden: Martinus Nijhoff.

Benson, J. K. (1982). "A framework of policy analysis," in: D. L. Roger, D. A. Whetten and Associates, Interorganizational Coordination. Ames: Iowa State University Press.

Braybrooke, D. and Lindblom, C. E. (1970). A Strategy of Decision, Policy Evaluation as a Social Process. New York, 1970: The Free Press.

Camhis, M. (1979). Planning Theory and Philosophy. London: Tavistock.

Collingridge, D. (1982). Critical Decision Making, A New Theory of Social Choice. London: Frances Pinter.

Elster, J. (1983). Sour Grapes: Studies in the Subversion of Rationality. Cambridge: Cambridge University Press.

Etzioni, A. (1968). The Active Society. London: Collier MacMillan.

Gregg, P. (1976). Problems of Theory in Policy Analysis. Lexington: Lexington Books.

Grondsma, T. (1983). TVC-Process and Speltheorie. Delft: (Mimeograph, in Dutch).

Faludi, A. (forthcoming). Critical Rationalism and Planning Methodology.

Friend, J. F., Power, J. M. and Yewlet, C. J. L. (1974). Public Planning: The Intercorporate Dimension. London: Tavistock.

Heclo, H. (1978). "Issues networks and the executive establishment," in: A. King (ed.), The New American Political System. Washington D.C.: American Enterprise Institute.

Hood, C. (1983). The Tools of Government. London: MacMillan.

King, A. (1978). "The American policy in the late 1970s: building coalitions in the sand," in: A. King (ed.), The New American Political System. Washington D.C.: American Enterprise Institute.

Lowi, T. J. (1979). The End of Liberalism. New York: W. W. Norton.

Mannheim, K. (1968). Ideology and Utopia. London: Routledge and Kegan Paul.

Mayntz, R. (1983). "The conditions of effective public policy: a new challenge for policy analysis," Policy and Politics 11 (2): 123-144.

Milward, H. B. and Francisco, R. A. (1983). "Subsystem politics and corporation in the United States," Policy and Politics 11 (3): 273-293.

Mitnick, B. M. (1980). The Political Economy of Regulation, Creating, Designing and Removing Regulatory Forms. New York: Columbia University Press.

Peterson, M. W. (1981). "Financial planning for the 1980s: a response to reality and competitions," Planning for Higher Education 9 (4): 1-5.

Popper, K. R. (1966). The Open Society and Its Enemies. London: Routledge and Kegan Paul.

Popper, K. R. (1974). "Replies to my critics," in: P. A. Schilpp (ed.), The Philosophy of Karl Popper. La Salle, Il: The Open Court.

Redford, E. S. (1969). Democracy in the Administrative State. New York: Oxford University Press.

Russell, B. (1971). A History of Western Philosophy (2nd edition). London: George Allen \& Unwin. 
Schulman, P. R. (1975). "Nonincremental policy making: notes toward an alternative Paradigm," American Political Science Review 69: 1354-1370.

Simon, H. A. (1976). Administrative Behavior: A Study of Decision-Making Processes in Administrative Organization (third edition). New York: The Free Press.

Solesbury, W. (1974). Policy in Urban Planning: Oxford: Pergamon Press.

Steinbruner, J. D. (1974). The Cybernetic. Theory of Decision: New Dimensions of Political Analysis. Princeton: Princeton University Press.

Warren, R. L., Rose, St. and Bergunder, A. (1974). The Structure of Urban Reform. Lexington: Lexington Books.

Weinrich, H. (1971). "Diskurs, Didaktik und die Diktatur des Sitzfleisches," in: J. Habermas and N. Luhmann (eds.), Theorie der Gesellschaft oder Sozialtechnologie. Was leistet die Systemforschung? Theorie - Diskussion. Frankfurt: Suhrkamp.

Whetten, D. A. (1982). "Issues in conducting research," in: D. L. Rogers, D. A. Whetten and Associates, Interorganizational Coordination. Ames: Iowa State University Press.

Wildavsky, A. (1974). The Politics of the Budgetary Process. Boston: Little Brown. 